\title{
Chapter 2. Dynamic Models of Language Evolution: the Linguistic Perspective
}

\author{
Andrew D. M. Smith \\ University of Stirling
}




\begin{abstract}
This chapter gives an overview of language variation and how the dynamics of language are explored through formal models. It briefly outlines the dimensions over which language structures can vary, then looks at some of the very different ways in which language change has been investigated (sociolinguistics, historical linguistics, evolutionary linguistics). It describes how dynamic models of change have been successfully used in all of these fields, and how they have shed light on many aspects of language dynamics, from the properties of language change through phylogenetic analyses of language history to computational and experimental models of cultural evolution.
\end{abstract}

\title{
2.1 Introduction
}

Language is probably the key defining characteristic of humanity, an immensely powerful tool which provides its users with an infinitely expressive means of representing their complex thoughts and reflections, and of successfully communicating them to others. It is the foundation on which human societies have been built and the means through which humanity's unparalleled intellectual and technological achievements have been realised. Although we have a natural intuitive understanding of what a language is, the specification of a particular language is nevertheless remarkably difficult, if not impossible, to pin down precisely. All languages contain many separate yet integral systems which work interdependently to allow the expression of our thoughts and the interpretation of others' expressions: each has, for instance, a set of basic meaningless sounds (e.g. [e], [1], [s]) which can be combined to make different meaningful words and parts of words (e.g. else, less, sell, -less); these meaningful units can be combined to make complex words (e.g. spinelessness, selling), and the words themselves can then be combined in very many complex ways into phrases, clauses and an infinite number of meaningful sentences; finally each of these sentences can be interpreted in dramatically different ways, depending on the contexts in which it is uttered and on who is doing the interpretation. Languages can be analysed at any of these different levels, which make up many of the sub-fields of linguistics, and the primary job of linguistic theorists is to try to explain the rules which best explain these complex combinations. The hallmarks of human language, which distinguish it from less powerful communication systems used by animals, are frequently characterised in terms of lists of so-called design features, such as those itemised over half a century ago by Hockett (1960) and others. Language is unique in its 
semanticity, productivity and mode of transmission: it is a system spread through cultural learning which consists of relatively fixed mappings between form and meaning, yet can effortlessly accommodate infinite novelty of expression. Language gets its massive expressive power from its duality of patterning or double articulation (Martinet, 1949): linguistic utterances are assembled from small meaningful units (morphemes) combined according to a set of morphosyntactic rules, while the morphemes themselves are built from a second set of meaningless sounds (phonemes) using a different set of phonological rules. Linguistic knowledge is fundamentally symbolic, made up of an inventory of arbitrary associations between forms and meaning (de Saussure, 1916), which can be composed into complex signals whose meanings can be derived from the meanings of their component parts and the way these are combined (Krifka, 2001). Human language is also characterised by recursion, where forms can contain embedded components where the part and the whole share a syntactic category (Kinsella, 2009); this particular feature has famously been proposed as the core component of the putative innate faculty of language (Hauser et al., 2002). These (and perhaps other) design features effectively delimit the differences between human language on one hand and animal communication systems on the other; yet they also underplay one of the most significant features of language, that it is characterised at every level by dynamism, massive diversity and constant change. Evans and Levinson (2009) point out that ' $[w]$ e are the only known species whose communication system varies fundamentally in both form and content' (Evans and Levinson, 2009, p.431), and we are likewise the only known species whose communication system is not fixed, but on the contrary is constantly changing. Notably, all languages exist in two separate manifestations: internally, as relatively persistent (though changing) representations inside human brains, and externally, as ephemeral, transitory utterances which are produced and received by interlocutors; much recent work on the evolution of language focuses on how properties of language can be seen as adaptive to the need to alternate between these internal and external manifestations. In the remainder of this chapter I explore some of the ways in which linguistic diversity is realised, and some of the perspectives we have gained on understanding its dynamic nature: in Section 2.2. I describe diverse dimensions along which languages can vary; in Section 2.3 I investigate different approaches to language change on different timescales; in Section 2.4, I explore some of the formal models which have been used to explore the dynamic nature of language. 


\subsection{Language diversity}

There are around 7000 languages spoken in the world nowadays (Lewis, 2005); the precise tally is, perhaps surprisingly, impossible to calculate accurately, for two important reasons. Firstly, the criteria used to determine whether any system of linguistic expressions, or linguistic variety, should count as a different language from another system of linguistic expressions are not measured solely on objective linguistic terms, but are tied up with political decisions and aspirations which can draw different conclusions about the 'languagehood' of particular linguistic varieties. Linguistic criteria, for instance, are most frequently expressed in terms of the mutual intelligibility of varieties: can speakers of variety A understand speakers of variety B (and vice versa) based on their linguistic knowledge of their own variety? If they can, then the varieties can reasonably be considered to be dialects of the same language; if not, then they can be considered different languages. In the absence of major physical obstacles which reduce opportunities for people to mix with each other, of course, adjacent communities frequently speak mutually intelligible varieties, and sometimes such communities can form chains or dialect continua across very large areas, such as the unbroken chain of mutual intelligibility running from Portugal through Spain and France to the foot of Italy. In communities in areas around the political borders, however, people often consider that they speak different languages from their neighbours across the border (e.g. French or Italian), even though their varieties are linguistically almost identical. The opposite situation is also true, where political considerations can lead varieties which are not mutually intelligible to be widely considered dialects of a single language. Due to the historical and cultural unity of China, for instance, the major varieties of Sinitic languages there (e.g. Mandarin, Cantonese) are widely considered to be dialects (Goddard, 2005), yet they are linguistically as distinct from each other as the separate languages of Italian, French, Catalan, Spanish and Portuguese in Europe (Coulmas, 2013). Changes in political identities can have linguistic repercussions, too, as can be seen following the break-up of Yugoslavia in the 1990s, which led to the demise of the unified language formerly known as Serbo-Croat and the active building in the new countries of multiple distinct successor languages (Serbian, Croatian, Bosnian, Montenegrin), so that linguistic identities could better reflect the new and developing political situation (Greenberg, 2004).

Secondly, despite the heroic efforts of field linguists who devote their careers to describing, documenting and cataloguing languages across the world, surprisingly few languages are studied in great detail, and in fact many remain completely unknown. Those languages we do know are dying out dismayingly 
quickly; almost half the languages ever known to us have disappeared in the last five hundred years (Nettle and Romaine, 2000), and estimates suggest that perhaps only a tenth of the languages spoken today will still be spoken at the end of the century (Krauss, 1992). This matters not just for the completeness of linguistic catalogues, but because languages are major repositories of the cultural knowledge of the communities which use them (Maffi, 2001), and the death of a undocumented language can mean the irrevocable loss of the traditional knowledge stored within its vocabulary and grammatical distinctions (Evans, 2010).

The pervasiveness of language diversity is regularly underestimated, however, and its significance underplayed. Below I will give a flavour of some of the countless ways in which languages vary, from their sounds to the way they assemble words, from their grammatical rules to the meanings they encode.

\subsubsection{Sounds}

One of the fundamental properties which gives language its expressive power is the duality of patterning described above (Martinet, 1949). All languages contain meaningless phonemes which can be used to build meaningful morphemes, but they differ widely in their number and type, in how the space of possible phonemes is divided up, and in the rules for combining the sounds together into larger units. I discuss each of these differences briefly below.

In terms of sound inventory size alone, some languages in Southern African differentiate up to 144 different phonemes, while Rotokas, spoken in Papua New Guinea, manages with just 11. Some common sounds, such as the voiceless stops $[\mathrm{p}],[\mathrm{t}],[\mathrm{k}]$ or the nasals $[\mathrm{m}],[\mathrm{n}]$, occur in the vast majority of languages across the world, 2 while other sounds have an extremely restricted geographical range, such as the labiodental flap [ $\mathrm{v}]$ which is used only in particular areas of Central Africa. Whole groups of sounds are subject to similarly wide variation: while fricatives like [f],[v],[s],[z] form an important part of the sound inventory of the vast majority of human languages, they are not found at all in Australian aboriginal languages such as Dyirbal (Dixon, 1972), Kayardild (Round, 2009) and Yorta Yorta (Bowe and Morey, 1999). Click consonants (such as the tut-tut sound used to express disapproval by English speakers), on the other hand, are found as phonemes only in Khoisan and Bantu

\footnotetext{
${ }^{1}$ In many languages, the precise number of phonemes is a matter for debate, primarily because it can be unclear whether some complex articulatory combinations should count as one consonant or as a sequence of consonants (Zsiga, 2013).

${ }^{2}$ Although not without some striking exceptions such as Arabic, which lacks /p/and Tahitian, which lacks $/ \mathrm{k} /$.
} 
languages in southern and eastern Africa (Clements, 2000).

Even when languages do use the same sounds as each other, their phonological status within each language can be different. For all speakers of English, for instance, the sounds [s] and [s] (the latter pronounced like 'sh') count as separate sounds, because they contrast with each other: changing from one sound to the other can produce a different word with a different meaning (e.g. sip-ship; gas-gash). Although Japanese speakers also use these sounds, however, they don't contrast in Japanese: instead they are predictable variants of the same sound, which is usually pronounced as [s], but is systematically pronounced as [J] whenever it occurs before the vowel $/ \mathrm{i} /$, as for instance in the word sushi (Goddard, 2005). These contrastive distinctions are vitally important to understanding and speaking a language, yet they are essentially arbitrary and can be extremely difficult to discern for non-native speakers: in Polish, for instance, there are two contrasting sounds [6] and [s] (e.g. [koc] 'mow' - [kos] 'basket'), which both sound extremely similar (roughly like 'sh') to English speakers who do not distinguish them.

All languages make use of changes in pitch, for instance to mark the boundaries of syntactic units, but again their status can vary quite remarkably: in English, we can raise the pitch at the end of a sentence to make a question out of a statement, but in languages like Mandarin, every word has a distinctive pitch associated with it, as can be seen in Table 2.1, which shows four different pronunciations of the sequence [ma], each with its own specific meaning. Languages like Mandarin in which pitch variations are used to distinguish different words are called tone languages, yet these also differ in the number of distinct tones they make use of, from simple tone languages like Shona which differentiate only two, to more complex ones which make many more distinctions (Ladefoged and Johnson, 2011).

[Table 2.1 approximately here]

Finally, the most notably diverse characteristics of sound systems concerns the phonotactic rules which govern the combinations of sounds allowed in a language. Polynesian languages like Māori have extremely simple phonotactic rules, with all syllables consisting of a single optional consonant followed by a vowel, yielding words like koko 'shovel' or kūao 'young animal' (Harlow, 2007), while Caucasian languages like Georgian allow notoriously complex clusters of multiple initial consonants which appear almost unpronounceable to speakers of other languages, such as prckvna 'to peel' or brdyvna 'to fight' 
(Butskhrikidze, 2002). Although all spoken languages have sound systems, therefore, the ways in which these are organised can be extremely variable, and the phonological distinctions which languages make appear to be arbitrarily fine (Pierrehumbert et al., 2000).

\subsubsection{Words}

Linguistic diversity is also particularly noticeable in morphology, the study of the minimally meaningful parts, or morphemes, from which words are made. Languages differ in terms of how much information each word contains, how their morphemes are combined into words, and how clearly defined the morphemes are within a word, each of which will be explored briefly in turn.

In an isolating language like Thai, illustrated in (2.1), almost every word contains just a single morpheme, while in a synthetic language like Swahili (2.2), words are considerably more complex, frequently containing multiple morphemes packaged together inside a single word. Most languages in fact lie somewhere between these extremes, and are characterised by a mixture of the two types of words. English, for instance, contains not only many monomorphemic words like cat, build or good, but also a considerable number of more complex multimorphemic words such girl-ish-ly or over-pay-ment.

(2.1) Thai (Goddard, 2005, p.3)

khăw dây àan năngs̆̈

he/she PAST read book

'he read a book'

(2.2) Swahili

tu-li-mw-on-a

we-PAST-him-see-IND

'we saw him'

We can also classify morphemes into roots, which cannot be further broken down, and which normally contain the main content of the word's meaning, and affixes which are attached to the root and modify its meaning in some way. The English word unhappiness, for instance, contains the root happy and two affixes un- and -ness which add additional semantic content to the core 
meaning. ${ }^{3}$ The order of roots and morphemes is extremely variable, although a detailed analysis of the inflectional morphology of almost 1000 different languages (Dryer, 2013b) shows that while languages vary across the spectrum from those which make exclusive use of suffixes (e.g. Central Yup'ik) to those which make almost exclusive use of prefixes (e.g. Kihunde), there is a clear cross-linguistic inclination towards suffixing. 4 This has been attributed to processing constraints: although both kinds of affix arise originally from distinct words which have fused with adjoining words, Hall (1988) shows that suffixes are likely to be preferentially understood by hearers because they allow easier and quicker identification of the content words. In addition to the use of prefixes and suffixes, however, some languages also show even more complex morphological patterns, where morphemes are more tightly intermeshed with each other: affixes can be placed either inside roots (e.g. Tagalog bili 'buy', b-um-ili 'bought'; sulat 'break', s-in-ulat 'was broken'), surrounding them (e.g German kauf-en 'buy', ge-kauf-t 'bought'), or intermeshed in more complex ways. Semitic languages like Arabic and Hebrew, for example, use template morphology based on roots, typically made up of three consonants, into which vowels and other consonants are inserted in different ways to derive specific meanings. The Arabic root $k t b$ 'write', for instance, yields both specific forms of the verb such as katab 'he wrote' and biyiktib 'he is writing' and separate words such as kitaab 'book', kaatib 'writer' and maktaba 'library', along with many others.

The third dimension along which we find considerable morphological diversity is the level of fusion within the forms, or how clearly distinguishable the individual morphemes are. In agglutinating languages, the boundaries between the morphemes are sharply defined, as can be seen in the Swahili example (2.2) above and by the Hungarian example (2.3), where a single word barátságosabban is built up from a series of clearly visible suffixes added in sequence to the root barát 'friend'. By contrast, in fusional forms such as the Latin adjective bon-us 'good', the shape of the individual morphemes is not clear; the grammatical information specifying the gender (masculine), number (singular) and case (nominative) of the adjective is all conflated into a single suffix -us which cannot be separated into distinct morphemes.

(2.3) Hungarian (Siptár and Törkenczy, 2000, p.26)

\footnotetext{
${ }^{3}$ Affixes are usually written with hyphens to denote that they cannot occur on their own, and must instead be attached either before the root (prefixes) on after the root (suffixes).

${ }^{4}$ Almost half (49\%) of the languages with inflectional morphology were classified as predominantly suffixing, with a further $15 \%$ showing a 'moderate preference for suffixes'; only $7 \%$ were classified as predominantly prefixing, with $11 \%$ showing a moderate preference and the remaining $18 \%$ having approximately equal levels of suffixing and prefixing.
} 
barát-ság-os-abb-an

friend-ship-ADJ-COMP-IND

'in a more friendly manner'

\subsubsection{Grammar}

On the grammatical level, too, individual languages show an enormous range of diversity, from the order in which words are assembled into sentences to the syntactic categories and patterns of agreement which are obligatorily expressed in a language, only a few of which can be mentioned here.

Word order is the most famous and widely cited typological feature of languages, and indeed the development of the whole field of linguistic typology can reasonably be traced back to Greenberg's famous paper on the basic word order in declarative sentences across languages (Greenberg, 1963). The three main elements of a sentence - subject (S), object (O) and verb (V) - are found in all six logically possible orders in different languages, although there is a notable preponderance of the two orders SOV and SVO, which together make up $89 \%$ of the languages which have a dominant word order in Dryer's (2013a) cross-linguistic survey of almost 1400 different languages.5 In English, of course, word order is used to indicate which role (e.g. the doer of the activity, the person to whom the activity is done) that each noun phrase is playing in the sentence and is thus relatively fixed. Many other languages, however, use a very different grammatical means, known as case marking, in which morphological affixes or function words accompany the noun phrases and/or the verb to mark these roles. In (2.4) we can see that each noun phrase in Japanese must be followed by a special functional postposition (here $g a, n i$, o) which provides crucial information about the relationship between the noun phrase and the verb ageta: the nominative marker ga follows the subject, the accusative marker $o$ follows the direct object, and the dative marker $n i$ follows the indirect object or beneficiary. In Swahili, by contrast, (2.5) agreement prefixes (here $a-,-k i-$ ) are added to different parts of the verb complex, to specify and classify both the subject and object of the verb.6

(2.4) Japanese

$\begin{array}{lllllll}\text { sensei } & \text { ga } & \text { gakusei } & \text { ni } & \text { hon } & \text { o } & \text { ageta } \\ \text { teacher } & \text { NOM } & \text { student } & \text { DAT } & \text { book } & \text { ACC } & \text { give.PAST }\end{array}$

\footnotetext{
${ }^{5}$ VSO accounts for $8 \%$ of languages, while the other three logically possible orders are all extremely rare: VOS is found by Dryer in 25 languages, OVS in 11, and OSV in just four.

${ }^{6}$ The numbers in the Swahili glosses (2.5) and (2.6) refer to the class of the noun (roughly equivalent to gender in European languages) with which the prefix is agreeing.
} 
'the teacher gave the book to the student.'

\section{(2.5) Swahili}
mtu a-li-ki-on-a
kifaru
person SUBJ.1-PAST.OBJ.7-see-IND rhinoceros
'the person saw the rhinoceros.'

Case marking itself can also be realised in an assortment of ways. Both (2.4) and (2.5) illustrate sentences containing transitive verbs with two distinct arguments, a subject $S$ and an object $O$, which are identified through different case and/or agreement markers, nominative markers for the subject and accusative markers for the object. In other sentences, however, the verb is intransitive, with just one logical argument $A$ (e.g. 'the boy smiled.'); in (2.6) we can see that Swahili marks this argument with the same subject marker (a-) that it uses for the subject of the transitive sentence in (2.5), i.e. the markings for $A$ and $S$ are identical, or $A=S$. In other languages, by contrast, the subject of an intransitive sentence is treated in the same way as the object of a transitive sentence, i.e. $A=O$. In the Basque examples in (2.7) and (2.8), for instance, both $O$ and $A$ appear in the absolutive case with no case marking, while the subject of the transitive sentence $S$ has its own special ergative suffix $-k$.

(2.6) Swahili

mtu a-li-lal-a

person SUBJ.1-PAST-sleep-IND

'the person slept.'

(2.7) Basque (Trask, 1996, p.151)

gizona heldu zen

man.ABS arrived

'the man arrived.'

(2.8) Basque (Trask, 1996, p.151)

gizona-k neska ikusi zuen

man.ERG girl.ABS saw

'the man saw the girl.' 
To complicate things further, many languages use both the Swahili-style nominative-accusative system and the Basque-style ergative-absolutive system to mark their arguments, and they even differ in the circumstances when each system is used. In languages like Lakhota and Guaraní, for instance, the marking of the transitive subject $A$ may depend on a number of different semantic features such as the degree of voluntary control the subject is considered to have over the activity being performed, or whether the sentence is considered to be an event or a state of affairs (Mithun, 1991). In the Australian language Dyirbal, the marking is determined by the semantic referent of the subject, with participants in the speech act (I and you) using the ergative-absolutive system, but other participants (third person pronouns, nouns) using the nominativeaccusative system. In Georgian, however, the determining factor is the tense of the sentence: the ergative-absolutive is used in the past but the nominativeaccusative is used in the present (Song, 2001).

\subsubsection{Meaning}

Linguists have also begun to document the enormous diversity in which meaning is conceptualised and encoded in languages. Space prohibits a full exploration of this vast area, but to give some idea of the scale of cross-linguistic semantic variation, I will concentrate on a fundamental and relatively welldefined part of meaning structure, the conceptualising of spatial relationships between objects.

In a major work exploring how spatial distinctions are expressed in around a dozen languages, Levinson and Wilkins (2006) found surprisingly profound diversity in the conceptualisation and linguistic encoding of topological relations, motion, and frames of reference, yet also that this diversity appears nevertheless to be constrained by underlying abstract dimensions of apparently universal relevance. Languages like English encode basic locative constructions, or responses to a question like 'Where is the X?', using a noun phrase to represent the figure, or focus of the scene, a form of the verb to be, and a prepositional phrase to represent the (back)ground of the scene, as shown in (2.9). Other languages, however, structure their basic locative constructions in very different ways, using case marking or spatial nouns instead of prepositions, 0 using multiple different locative verbs (e.g. equivalents of 'stand', 'sit', 'lie', 'hang') depending on the shape or function of the figure, even using no verbs at all, or using highly specific dispositional predicates which precisely

\footnotetext{
${ }^{7}$ Or rather adpositions, a cover term encompassing both prepositions which occur before their arguments as in English, and postpositions which occur after their arguments in languages like Japanese.
} 
orientate the figure and ground (Brown, 2006).

(2.9) the apple is in the bowl

NP BE PP

figure ground

'the apple is in the bowl.'

After a detailed investigation of the kinds of scenes which can be described using a language's basic locative construction (BLC), Levinson and Wilkins (2006) propose a topological space hierarchy in which all languages in their sample encode core scenes like 'cup on table' and 'ball under chair' using their BLC, but only some encode adhesion ('stamp on letter') in this way, fewer encode scenes in which the ground or the figure is pierced ('arrow in apple', 'apple on skewer') and fewer still encode scenes in which the ground is a human or other animate being ('ring on finger'). Looking at adpositions alone, the same eight scenes are encoded using between zero and seven different lexical items in the sample languages, with a wide range of distinctions being made (e.g. both Dutch and Yélî Dnye require seven adpositions, but while Dutch encodes different types of surface contact ('stamp on letter', 'cup on table') identically, Yélî Dnye conflates adhesion ('stamp on letter', 'ring on finger') under the same adposition. They conclude that abstract concepts like 'contact' and 'horizontal support' are more likely candidates for universality than are concepts like IN and ON, contrary to conclusions which had been drawn after perusal of European languages alone (Levinson and Wilkins, 2006, pp. 519-520).

Famously, Talmy (2000) presented evidence of a major split between ways in which simple motion events are linguistically encoded, which can be seen even in relatively closely related languages such as English and French. In English (2.10), motion events are commonly expressed using verbs which describe the manner in which the motion takes place (e.g. slither, crawl, slide) and prepositional phrases describing its direction or path, while in French (2.11) the same concepts are expressed using verbs specifying the direction of the movement (e.g. enter, climb, descend) and an optional participle describing its manner (Israel, 2014).

(2.10) the children jumped down the stairs manner direction

(2.11) French (Israel, 2014, p. 173)

$\begin{array}{lllll}\text { les écoliers } & \text { ont } & \text { descendu } & \text { l'escalier } & \text { en sautant } \\ \text { the schoolchildren } & \text { AUX } & \text { go.down.PST } & \text { the staircase } & \text { jumping } \\ & & \text { direction } & & \text { manner }\end{array}$


'the schoolchildren jumped down the stairs'

Spatial frames of references are required to describe the relationship between figure and ground when they are separated in space, and Levinson and Wilkins (2006) also show that there are three systems used in natural languages which differ in what they use as the frame of reference within which the figure can be located: the intrinsic system uses a particular facet of the ground (e.g. 'in front of'), the relative or egocentric system uses the observer's own body (e.g. 'to the left of'), and the absolute system uses a set of conventionalised fixed points (e.g. 'south of'), with languages varying in which of these systems they employ most frequently. Australian languages such as Guugu Yimithirr (Levinson, 1997) and Warrwa (McGregor, 2006) are fascinating because they use an absolute frame of reference based on the cardinal compass directions almost exclusively, even for small-scale descriptions like the 'fork lies to the south' (Foley, 1997) and for body parts 'my north arm' (McGregor, 2006). Speakers of such languages are therefore always aware of the absolute position of objects, and their descriptions of items in books or on screens consequently change depending on the orientation of the pictures (Deutscher, 2010). Compass directions are not the only foundation of absolute frames of reference, however, with other systems being based on the prevailing ecological topography of the area in which the community lives: Jaminjung's frame of reference is based on the main river-drainage system (upstream-downstream) (Schultze-Berndt, 2006) and Tzeltal's is based on the direction of the main mountain range (uphill-downhill) (Brown, 2001, 2006), while Yélî Dnye's is based on the prevailing winds and on the topography of their island (central/ mountainwards - peripheral/seawards) (Levinson, 2006).

This section has given a flavour of the range of ways in which linguistic diversity is manifested in the world's languages. In the next section, I focus on linguistic dynamism, its source, and some of the timescales over which it can profitably be investigated.

\subsection{Language change}

Despite the fervently expressed desires of many commentators on language, who can regularly be found bemoaning aspects of the putative degeneration of modern language in the columns of newspapers around the world, all living languages are in an unceasing and indeed unavoidable state of flux. They change in countless different ways, from the very conspicuous and deliberate coining of new vocabulary to reflect changes in the artefacts and cultural 
concepts we want to refer to (e.g. selfie, vaping) to more obscure and unintentional cases of reanalysis, where the internal structure of a construction is understood in a different way from that which was originally intended (e.g. the original structure of the word hamburg-er was reanalysed as ham-burger, leading to novel coinages like cheese-burger) (Trask, 1996). Some changes in pronunciation can be understood straightforwardly in terms of a general tendency to reduce the effort required for articulation, by reducing the amount of movement required within the mouth (e.g. the pronunciation of words like better with a glottal stop instead of [t]), or by pronouncing sounds which occur close together more like one another (e.g. the pronunciation of words like input as im-put, with the nasal being articulated in the same part of the mouth as the following consonant).

The terms language change and language evolution are both wide-ranging and frequently overlapping in their denotation: sometimes synonymous, yet also often set in opposition to each other, both are frequently used to refer to wildly different notions on diverse timescales, from specific changes in the way a particular word is used at a particular point in time, to the biological evolution of particular cognitive capacities which have allowed us to learn and use language. In the following sections I will distinguish in turn three different aspects of language change which models have successfully been used to explore: the ubiquity of linguistic variation, the ultimate source of the constant state of flux in which language exists and an inevitable consequence of the way human communication works; the identification of historical relationships between languages and their classification into metaphorical family trees; and interactions between biological and cultural evolution from which language initially emerged.

\subsubsection{Variation}

People speak differently from the way in which their parents speak, and differently again from the way in which their children speak, even while they consider themselves (and are considered by others) to be speakers of the same language. Even within the same generation variation in people's pronunciation of certain sounds or in their usage of particular words and constructions gives other people crucial information about their identity: where they come from, their socio-economic status and ambitions, the groups of people they spend time with, and much more.

The systematic study of linguistic variation was originally spearheaded by sociolinguists such as Labov (1972) and Trudgill (1972), who introduced the idea of a formal linguistic variable which can be realised as multiple different 
variants in different contexts. Labov (1972)'s pioneering work was focussed on the isolated island of Martha's Vineyard in Massachusetts, where islanders often used particularly idiosyncratic pronunciations of certain diphthongs. He found correlations between the extent to which these pronunciations were used with social variables such as age, occupation and geography, and showed that the idiosyncratic pronunciations were being used as a linguistic marker of the speaker's identity, in particular their commitment towards wanting to remaining on the island, in the context of a collapsing fishing-based local economy and improvements in travel which had led both to large growth in the number of casual visitors to the island and to increasing opportunities for islanders to move to the mainland for work. At the same time, Trudgill (1972) was one of the first to quantify not only the striking connections between social class and the use of prestige variants, but also to show how the speech context itself also plays an important role, demonstrating that all speakers use fewer overtly prestigious forms as the context becomes increasingly informal. He also showed systematic differences between men's and women's speech which have been echoed in many subsequent studies: men consistently use more vernacular forms and women use more standard forms. Many explanations for these differences have been suggested, from claims that women are more aware of the social consequences of the way they speak to suggestions that the increased use of vernacular forms by men (particularly working-class men) is an expression of their masculinity (Holmes, 2013). Frequently, however, variation is better explained in terms of social network properties, with denser social networks where everyone knows each other tending to inhibit linguistic change and looser social networks being more receptive to innovation. As Milroy (1980) put it in his famous study of working-class communities in Belfast, 'the closer an individual's network ties are with his local community, the closer his language approximates to localized vernacular norms' (Milroy, 1980, p.175). Interestingly, Milroy also found more complex interactions between gender and social networks too, showing that as young women rather than men came to be chief breadwinners in the face of recession and the loss of traditional heavy industry which had been strongly male-dominated, their social networks became closer than in earlier generations, and their language reflected what had previously been considered markers of masculine speech.

The inevitably of variation in language stems from the fact that language is fundamentally a social interactional phenomenon (Croft, 2000) between people who belong to different, though potentially overlapping, social communities and have different individual experiences. Social communities are internally cohesive and externally distinctive collections of people who have come together because they have shared practices, beliefs or knowledge which 
are lacked by non-members of the community (Trousdale, 2010). We each belong to multiple interactive communities and sub-communities defined by our work, family, friends and recreational activities, in which we negotiate and express facets of our identity. Bolinger (1975) highlights that 'there is no limit to the number of ways in which human beings league themselves together for self-identification, security, gain, amusement, worship, or any of the other purposes that are held in common; consequently there is no limit to the number and variety of speech communities that are to be found in society' (Bolinger, 1975, p.333). Our decisions about language use are a crucial part of this identity creation and maintenance, both within and outwith these communities. Moore (2004), for instance, shows how particular aspects of grammatical variation (e.g. using non-standard 'I were', 'he were') became used increasingly frequently by members of an emerging group of 'townie' girls in a school in north-west England, as they sought to signal their group identity as different from other established groups of girls at the school. In many multilingual societies, indeed, there are clear demarcation lines between different domains in which different languages are used, often with an official, prestigious language being used in more formal and religious contexts, and vernacular languages being used in informal contexts with friends, in the market and at home (Holmes, 2013). In truth, though, monolingual societies also display similar kinds of linguistic division between domains of use, albeit that they are more subtle because they are expressed through the use of different varieties of the same language rather than through different languages. The individuality and variability of our complex social networks and of our experiences within them is reflected in the individuality and variability of our linguistic repertoires, both in the ephemeral external linguistic behaviour we produce, and in the longer-lasting internal linguistic representations stored within our brains.

The process of linguistic communication itself is also inherently variable. Communication has often been thought of as a simple deterministic computational process in which the speaker's thoughts are encoded into an utterance, conveyed to the hearer, and then decoded back into meanings; assuming that both parties have the same encoding/decoding algorithms, then communication is successful (Shannon, 1948). Much work in the philosophy of language and in what is now known as pragmatics (Grice, 1975), however, showed that such a model cannot account for the nuances and detail of real-life communication, where the same utterance can be interpreted in radically different ways depending on the context in which it occurs (and, indeed, where different utterances can be interpreted identically). Communication is therefore not a simple encoding-decoding process, nor if, even we relax the assumption that interlocutors have the same algorithms, a process of 'reverse engineering' though which 
the hearer reassembles the speaker's meaning (Mufwene, 2002; Brighton et al., 2005), but rather it is a system based on the complementary and co-operative processes of ostension and inference (Sperber and Wilson, 1995; Scott-Phillips, 2014; Smith and Höfler, 2015), which relies crucially on the interlocutors being able to recognise and exploit their mutual common ground (Clark, 1996). Common ground is both wide-ranging and multi-faceted, including not only the interlocutors' fundamental shared recognition of each other as a potential conversation partner, but also a shared understanding of each other's intentions and of the joint goal of their conversation (Tomasello et al., 2005). It encompasses an understanding of relevant material from the communicative context, as well as shared attitudes, shared beliefs and shared conventions. These conventions, crucially for linguistic communication, include knowledge of the conventional (and of course arbitrary) meanings of particular words and constructions. Much common ground derives, of course, from the shared communities to which people belong, the distinctive behaviours and specialised vocabulary they share, but indeed every pair of interlocutors also has their own interpersonal common ground derived from their previous shared experiences together, and from the things one person knows their interlocutor knows about.

Common ground allows people to communicate successfully by providing a backdrop against which both ostension and inference can take place. The speaker 8 can act out an appropriate ostensive act, one whose deliberate and atypical nature both marks it as being intended as a communicative and encourages the hearer to interpret it in an opportune way. Having identified the signal as communicative, by its ostensive nature, the hearer then uses the evidence contained within the speaker's signal and the broader communicative context to inferentially construct a relevant meaning which makes sense of the signal. This process of meaning construction is not deterministic at all; rather it is inexact, ambiguous and underspecified, based on creative processes of inference and conceptual blending (Fauconnier and Turner, 2002; Höfler and Smith, 2009) which are inherently unstable and equivocal. Moreover, the individual nature of our cognitive representations means that, no matter how much common ground interlocutors share, there will inevitably be some (however minor) variation between their understandings of the same communicative episode and therefore between their internal linguistic representations; it is this variation which leads inexorably to the ubiquitous variation which pervades language (Smith and Höfler, 2015).

\footnotetext{
${ }^{8}$ Communication is not only spoken, of course, but I use the terms speaker and hearer in a general sense to indicate the person performing the communicative act and the person to whom the act is addressed.
} 


\subsubsection{History}

The fundamental goals of historical linguistics are to identify historical relationships between languages, particularly in cases where there is no corroborating written evidence, to describe the histories of languages and groups of languages, and, ultimately, to develop a comprehensive theory of language change (Harrison, 2005). When a language is spread over a reasonably large geographical area, the changes it undergoes will inevitably be different from area to area, yielding different dialects of the language; eventually (particularly when travel between dialect groups is difficult, as in pre-modern times), these dialects therefore tend to separate into different, mutually unintelligible languages. Languages which were once dialects of the same language (e.g. French and Spanish were originally dialects of Latin), but have diverged in this way, are said to belong to the same language family. This genealogical analogy is very widespread in historical linguistic terminology, so languages in the same family are said to be 'genetically' related to each other and to their 'common ancestor' language, and language families and higher groupings such as language 'phyla' are conventionally illustrated by linguistic 'family trees', but it is important to note that this terminology merely reflects an extended metaphor, and does not imply any true biological connection (although see subsection 2.4.2 and subsection 2.4.3 for further discussion of work seeking to draw connections between genetic and linguistic features).

The establishment of such 'genetic' relationships among languages can be acknowledged when a particular feature the languages share is unlikely to have arisen independently or been borrowed between them, and can therefore best be explained in terms of the feature's 'inheritance' from a common ancestor language. In order to reduce the possibility of independent identical innovation in the languages under investigation both natural resemblances (e.g. onomatopoeia like 'cuckoo') and chance resemblances (e.g. in the unrelated languages Hawai'ian and Greek, the word for honey is meli (Trask, 1996)) must be excluded from the analysis. This is primarily done by finding frequent and systematic correspondences between lexical items in the languages, through the painstaking technique of the comparative method, the 'gold standard' (McMahon and McMahon, 2005) of historical analysis. Table 2.2, for example, shows a small part of a system of regular correspondences in the initial consonants of words in English, Dutch and German: in every row of the table (and in many more examples not shown), the words have the same meaning, and there is a systematic relationship in their form where initial [p] in English corresponds to [p] in Dutch and to [pf] in German. 
[Table 2.2 approximately here]

The systematicity and predictability of these correspondences, therefore, is regarded as convincing evidence that we are dealing not with chance resemblances, but instead that the languages all belong to the same language family (West Germanic), and that they are all culturally descended from a common ancestor language or proto-language (proto-Germanic), possibly spoken roughly around the same time as Latin, but for which we have no confirmatory written records. The words in these correspondence sets are taken to be modified reflexes of a single item in the original proto-language, or cognates. Through a process of comparative reconstruction, which uses these correspondences to posit sounds in the ancestor language that could plausibly have developed into the sounds in the descendant languages, the words in the proto-language can be reconstructed with some degree of confidence. For example, for the correspondence set shown in Table 2.2, we would reconstruct an original sound *p, 9 which later became the affricate /pf/ in German but remained the same in English and Dutch, on the grounds that a change from /p/ to /pf/ is more frequent cross-linguistically and consequently more natural than the converse. The comparative method has been used to identify many language families and reconstruct putative proto-languages across the world; one of its greatest achievements was indeed the identification that many reconstructed protolanguages in Europe and North India were themselves related to each other, and thus that they were all descended from the same ancestor language, which we now know as Proto-Indo-European (Trask, 1996).

It is important to note, however, that such conclusions of descent from a common ancestor rests on some key assumptions. Most fundamentally, the comparison of lexical items across languages depends on the universal property of human language we saw in Section 2.1, that linguistic signs are intrinsically arbitrary (de Saussure, 1916), so the connection between words and their meanings is not motivated by any perceptual similarity but merely determined by cultural convention. Systematic similarities between languages are therefore indicative of shared linguistic ancestry because they would otherwise be surprising and unexpected. The arbitrariness of lexical items thus makes them much more suitable for the comparative method than other linguistic items such as syntactic constructions, where relationships between form and meaning are much more motivated and thus much more likely to recur across languages which are not related to each other.

\footnotetext{
${ }^{9}$ The preceding asterisk here signifies that the form is not attested, but reconstructed using the comparative method.
} 
Secondly, the Neogrammarian axiom of the comparative method is that sound change is assumed to be regular in each daughter language, and affects all items with the relevant sound in the relevant context (e.g. the initial *p in Table 2.2) simultaneously and with the same result. In fact, due to the ubiquity of variation in language that we have already seen in subsection 2.3.1, and particularly the discovery that sound changes actually proceed through a language a few words at a time, through a process of lexical diffusion (Chen and Wang, 1975), we know that this axiom is not warranted, at least in its strongest form. Over the long timescales usually under consideration by historical linguists, however, the result of a sound change progressing through lexical diffusion is 'virtually indistinguishable' (McMahon and McMahon, 2005) from a change occurring universally and simultaneously, and the axiom can thus be recast as an approximation which holds sufficiently for the comparative method to remain valid.

Thirdly, and more problematically, however, the construction of language family trees must necessarily exclude contact-induced changes, or borrowings, which can cause spurious correspondences between unrelated languages and potentially undermine the comparative method (McMahon and McMahon, 2003). Borrowings need to be excluded from consideration before comparisons are undertaken, but it is unfortunately not always a trivial task to identify them: whenever linguistically diverse cultures come into contact with each other, a degree of multilingualism always ensues, which in turn facilitates the propagation of linguistic features from one group to the other. Contact-induced change is usually motivated by social factors like prestige, power and trade relationships described in subsection 2.3.1, which can have wide-ranging effects on different linguistic systems. Although lexical items are usually thought to be the area most susceptible to borrowing (Sankoff, 2004), phonological, morphological and grammatical structures can also be borrowed in the right circumstances (Heine and Kuteva, 2005, 2006). The most common approach to weeding out borrowings from an analysis is to focus on basic and (near-) universal vocabulary items (e.g. kinship terms like mother, father, body parts like head, eye, and universal natural phenomena like river, sun) which are putatively 'less subject to replacement than other kinds of vocabulary' (Campbell, 2004, p.178), and these are the basis for many of the phylogenetic models discussed in subsection 2.4.2.

Finally, the evidence on which the comparative method depends is inevitably eroded by the same language change over time that it seeks to exploit to find the historical relationships. The more time that has passed since an ancestor language was spoken, the less evidence of shared ancestry will remain in its descendants, and thus the more problematic that ancestry will be to prove. 
Importantly, the rate of linguistic change is variable to such an extent that it is all but impossible to date linguistic changes without independent physical evidence such as written inscriptions of some sort (McMahon and McMahon, 2000).

These issues clearly show that the comparative method is certainly not a panacea for historical linguists, but it nevertheless remains an extremely useful tool which can shed considerable light on relationships between languages, as long as careful consideration is given to the data to which it is applied, and every effort is made to exclude inappropriate data to minimise the potential problems. Unfortunately, the necessary decisions on such data exclusions often require the prospective analyst to have a very considerable level of knowledge of the languages to be compared, and this high barrier to the valid use of the comparative method has led to the development of other superficially attractive but fundamentally flawed classificatory techniaues such as mass comparison (often now called multilateral comparison) (Greenberg, 1987; Ruhlen, 1991, 1994). This contentious and highly controversial method has been severely criticised (Campbell, 1988; McMahon and McMahon, 1995) due to its methodology, which deliberately short-circuits the painstaking rigour of the comparative method in favour of collecting basic vocabulary items from a massive range of different languages, tabulating them and simultaneously comparing them to 'automatically' identify language groupings by noting the patterns which will inevitably be found. The twin requirements of frequent systematic correspondences to control against accidental similarity and of the comparative reconstruction of ancestral forms through regular and plausible sound change are both cast aside in favour of undefined criteria for determining matches in both form and meaning, which serve to render the technique of mass comparison devoid of scientific validity and its conclusions indistinguishable from chance (Campbell, 2004). As Aitchison (1996, p.172) puts it: '[c] hance resemblances are easy to find among different languages if only vague likenesses among shortish words are selected.' Most breathtakingly, in response to complaints that much of the primary data used in the initial applications of mass comparison was strewn with errors, it has even been claimed with hopeless optimism that inaccurate or incomplete data supposedly has 'merely a randomising effect' (Greenberg, 1987, p.29) on mass comparison and does not impact on its reliability.

Mass comparison's extremely liberal acceptance of any evidence in favour of languages being related, no matter how vague or tenuous, makes it a methodology which is 'very good at finding patterns, but no good at all at telling us whether those patterns mean anything' (McMahon and McMahon, 2005, p.22). The key issue is that mass comparison conflates the process of hypoth- 
esis generation with that of hypothesis testing: although historical linguists have indeed always begun with observing resemblances between languages and wondering whether they might be related, this is far from assuming that an occasional resemblance actually proves that a historical relationship existed. Ostensibly comprehensive hierarchical linguistic classifications have been produced through the application of mass comparison (Ruhlen, 1994), though they contain extremely contentious language families such as Amerind ("Ithis] classification and its attendant methods must be rejected' (Campbell, 1988, p.610)) and Indo-Pacific ('This idea lacks any substance' (Dixon, 1997, p.35)), and even more controversial groupings of language families into macrofamilies such as Eurasiatic, finally culminating in the wildly speculative and unfounded 'last common ancestor' of all existing languages, Proto-World, angrily condemned as 'at best a hopeless waste of time' (Campbell and Poser, 2008, p.393).

Although mass comparison has effectively no linguistic validity, it is nevertheless not without appeal outside the field of historical linguistics, precisely because of the illusory linguistic classifications it can produce in areas where historical linguists acknowledge that the data is no longer robust enough for the comparative method to work. One of the most famous uses such classifications have found is in the comparison of genetic and linguistic trees (CavalliSforza et al., 1988) discussed in subsection 2.4.2, which sought to reconstruct human phylogeny by finding correlations between trees built from measures of genetic diversity between human populations and pseudo-historical linguistic trees based on mass comparison (Greenberg, 1987).

\subsubsection{Evolution}

The primary aim of evolutionary linguistics, on the other hand, is to explain the transition to language, how our unique communication system emerged from a non-linguistic system. Historically, the predominant view of language has been as an autonomous module within the brain, a language organ containing the universal structures which form the basis for all human languages (Chomsky, 1965). This view has been traditionally underpinned by the argument from the 'poverty of the stimulus', the claim that the linguistic evidence to which children are exposed is not sufficient to acquire the grammar they end up with (Chomsky, 1980) (although see Pullum and Scholz (2002) for a detailed empirical assessment which found no convincing support for the claim). An evolutionary account of this nativist view of language was developed by Pinker and Bloom (1990), based on the assumption that the language organ evolved biologically though natural selection for language learning, and mak- 
ing use of the Baldwin effect, through which traits which are originally acquired through learning can become encoded genetically, when learning changes the evolutionary environment so that genes which encode the learnt behaviour explicitly are selected for (Deacon, 1997). Although the Baldwin effect has been demonstrated in some evolutionary models where genotype and phenotype are directly connected (Turkel, 2002), it is not found in more biologically plausible scenarios (Yamauchi, 2001), and the encoding of specific linguistic parameters as envisaged by Pinker and Bloom (1990) can only occur when the linguistic target is fixed (Munroe and Cangelosi, 2002). When language is changing even very slowly, selection actually works in favour of neutral genes rather than specialised genes which encode linguistic principles directly, effectively because biological evolution is not able to keep pace with a moving target (Chater and Christiansen, 2009; Chater et al., 2009).

As a result of this, attention in evolutionary linguistics has largely shifted to the cultural evolution of language as an explanatory mechanism, turning the problem on its head to suggest that the languages themselves have evolved in order to become more learnable by human brains, and thus persist over time among human populations, rather than our brains evolving to learn language (Christiansen and Chater, 2008). According to cultural accounts, the requirement for language to oscillate continually between its internal and external manifestation as it is learnt and used leads to the emergence of languages which have adapted to be learnable by humans (Kirby, 2000; Zuidema, 2003; Smith, 2008). The burden of evolutionary explanation thus shifts to identifying the minimal set of cognitive capacities which can support the sharing of inferable cultural conventions (Smith and Kirby, 2008); these capacities need not be specific to language at all, but could have evolved biologically for some other purpose; they may be universal pressures such as memory or processing constraints but they may only apply in particular circumstances (or niches) such as populations with small numbers (Nettle, 1999) or with a relatively high number of second-language learners (Lupyan and Dale, 2010), as we will see in subsection 2.4.3.

Explanations of both the biological evolution of relevant cognitive capacities and the cultural evolution of language in dynamic populations of cognitively adapted individuals are required for a full explanation of the emergence and evolution of language, and it has become increasingly clear that the interaction between biology and culture, too, is likely to be vital: biology provides cognitive adaptations which influence how we interact with each other, while these cultural interactions can cause qualitative structural changes to language itself. One profitable way of conceptualising this to consider language as a complex adaptive system (Gell-Mann, 1994; Beckner et al., 2009), 
a system where the linguistic structure is a set of emergent properties derived from communicative interactions, without any system-wide central guidance or optimisation (Hopper, 1987; Bybee, 2006). The very different evolutionary timescales involved, however, mean that we are probably dealing with at least three separate complex adaptive systems, which interact with each other in interesting yet complex ways (Kirby and Hurford, 2002).

\subsection{Dynamic models of language}

The utility of a formal model lies in the rigour with which it allows theoretical mechanisms to be tested and evaluated. A model is always a simplification of the real system and thus potentially inaccurate in some important detail, but the explicit specification of the assumptions behind the model mean that the consequences of the design decisions which have been implemented can be clearly demonstrated. There is a continuum of complexity on which models can be placed, from those which deliberately ignore many details so that they can zoom in on some potentially crucial attributes of the system, to those which embrace the details in an attempt to be more realistic, yet in doing so produce models whose results require much more nuanced interpretation and are less likely to yield clear conclusions (Smith, 2011). Various types of formal models have been used over the last few decades to explore many dynamic aspects of language, from computational simulations and mathematical models to more recent experimental approaches. In this section I will look at how these different types of modelling have shed light on different aspects of language dynamics, from the general properties of language change through phylogenetic analysis of language history to computational and experimental models of the cultural evolution of language.

\subsubsection{Models of language change}

Mathematical models have frequently been used to explore the general dynamics of language change, using a variety of evolutionary frameworks. Exemplar models, for instance, use a very general framework in which (linguistic) categories are made up of sets of individual tokens which are grouped together by their shared labels and organised in terms of some measure of similarity. The individual tokens represent usage events: every time the category is used, a new token is added to the system. Exemplar models are thus very good models of linguistic variation: every category contains many different variants, and different speakers therefore have different representations of the categories, 
reflecting their different experiences. The same exemplar categories can also be seen to form a distribution from which individuals' production of linguistic variants is drawn, and indeed each production yields another exemplar to be added to the category. In an evolutionary model, some of these variants must be selected according to some criteria, so that they are differentially produced over other competing variants. Wedel (2006) uses a series of exemplar models like this to show in detail how genetic drift results in the random fixation (when the whole community uses the same variant) of variants by pruning variation, how small increases in selection bias can result in the inhibition of sound changes where they would eliminate a functional contrast like those described in subsection 2.2.1 and, conversely, how contrast can be shifted across segments in cases of low functional contrast.

Baxter et al. (2009)'s framework focuses explicitly on the types of selection mechanisms which can work on variants of a linguistic variable. Their model, which is based on Hull (1988)'s general analysis of selection in evolutionary systems as developed into Croft (2000)'s theory of utterance selection, makes a crucial distinction between the replicators, the linguistic entities which are replicated, and the interactors, the language users whose interaction with each other causes the differential replication of the linguistic entities, yielding four qualitatively different selection mechanisms, dubbed neutral evolution, neutral interactor selection, weighted interactor selection and replicator selection. Neutral evolution is directly equivalent to the solely random process of genetic drift, which can, as Wedel (2006) showed, produce random fixations without any need for true selection at all. Their mechanisms of interactor selection naturally focus on how the structure of the networks and communities in which the speakers interact can have substantial impacts on the replication of variants: in neutral interactor selection, frequencies of interaction between speakers is the only relevant factor; in weighted interactor selection, certain interactors are preferred over others, due to different social valuations on them and the social groups they belong to, and so the variants they use are indirectly preferred. In the final mechanism, replicator selection, the linguistic variants themselves have different social valuations which lead directly to their differential replication. Baxter et al. (2009) used their framework to investigate a notable theory of new dialect formation in isolated colonial communities such as New Zealand after the arrival of British settlers (Trudgill, 2008), which held that sociolinguistic features like identity and prestige play no part, but that the new society effectively begins with a blank slate in which linguistic variants have no pre-existing social values attached to them, and so the adoption of new variants is driven solely by the frequency of interaction between interlocutors (i.e. neutral interactor selection). Their analysis showed that although the 
linguistic characteristics of New Zealand English were indeed consistent with change simply through accommodation to interlocutors and frequency of interaction, as Trudgill had suggested, it was inconceivable for this mechanism alone to have been able to produce the level of dialect homogeneity which was actually seen in New Zealand in the available timescale, and therefore that some differential social valuation of either the interlocutors (weighted interactor selection) or the variants they used (replicator selection) would have been required.

Blythe and Croft (2012) used the same evolutionary framework to investigate the general mechanisms of propagation in language change, or how a new linguistic variant is diffused through a community and becomes conventionalised so that it replaces the original convention. Such replacement events, in common with many natural processes, are characterised by a trajectory which follows an approximate sigmoid S-curve, progressing from a slow beginning through a phase of rapid acceleration and a slow approach to completion. In particular, they focus on a systematic exploration of (Baxter et al., 2009)'s selection mechanisms, to see which of them can yield the characteristic diffusion curve, finding that replicator selection is 'almost certainly an essential mechanism for language changes that follow an S-curve' (Blythe and Croft, 2012, p.293). Interestingly, they find that the mere existence of any differential valuation of variants is enough: it is not required for the emergence of an $S$-curve for individuals in the community to give variants the same values, nor for those values to remain constant. Their hedging of replicator selection as almost certainly essential stems from their finding that although they did manage to simulate an appropriate trajectory with weighted interactor selection alone, this was only possible under rather implausible conditions where the population was increasing exponentially over time and each new group into the populations weighted their immediate predecessors highly. A similar finding was reported by Gong et al. (2012), using a slightly different kind of evolutionary model based on the Price equation for the description of evolutionary processes (Price, 1970) in combination with the Pólya urn model of dynamics from epidemiology, which confirmed that replicator selection (which they term variant prestige) is the key selective pressure which drives the adoption of new variants in a population.

A more specific dynamic model of language change is presented by Kandler et al. (2010), who are interested in modelling the process of language shift, where members of a multilingual speech community abandon their original language for another language, frequently because the new language is seen as more useful in achieving social mobility or in providing access to greater economic opportunities (McMahon, 1994). Kandler et al. (2010) focus in par- 
ticular on the shift from Celtic languages to English in Britain and Ireland over the last couple of centuries, and intriguingly show that, although monolingual speakers of the language with lower prestige always disappear, the minority language itself can still persist in a bilingual community, as long as there are both sufficient bilingual speakers and sufficient pressure on monolinguals in the high-status language to become bilingual. Applying this to the current situation of Gaelic in Scotland, they suggest, perhaps optimistically, that around 860 English speakers need to become bilingual in Gaelic each year for the language to become stable. See also the papers by Grin (Chapter 21), Wickström (Chapter 22) and Uriarte (Chapter 23) in this volume for further discussion of minority languages.

\subsubsection{Models of language history}

Very different kinds of evolutionary model are used in phylogenetic approaches to historical linguistics, which seek both to infer language histories and also to use linguistic history as evidence for hypotheses in other disciplines, such as human dispersal or human genetics.

The basic foundation of phylogenetic analysis is the cognate set, based on a list of words in various languages corresponding to a standardised universal list of meanings; the most widely used lists are the Swadesh vocabulary lists of 100 or 200 core items (Swadesh, 1952), who originally created much longer lists, but settled on the smaller sets after various exclusions were necessary, most notably because the meaning was not sufficiently culturally neutral (e.g. snow), because meaning differences were not reliably lexicalised across languages (e.g. leg/foot), or because items were not reliable independent of each other (e.g. wife/woman). The cultural neutrality of the Swadesh lists is problematic, and this has led to the creation of various culturally-specific modified Swadesh-style lists for use in phylogenetic analysis for specific parts of the world, for instance for South-East Asia and the Andes. There are also issues about semantic ambiguities in the lists, which were originally defined using single English words without further explanation (e.g. should 'cloud' refer to white cumulus or to black rainclouds?); Kassian et al. (2010) have therefore developed a series of more detailed, disambiguating semantic specifications for the standard 100-item list to provide a helpful standard for list compilers, who need to enter a word into the list for each language which is being analysed. This step is crucial to any phylogenetic model, and requires the specification of well-defined criteria for inclusion. Swadesh (1952) originally suggested that items on the list should be common, as morphologically simple as possible, and single words rather than phrases. The massive cross-linguistic semantic 
variation and ambiguity we saw in Section 2.2, however, can lead to severe problems in deciding which forms should be included (McMahon and McMahon, 2005). Many languages, for instance, have unrelated near-synonyms (e.g. English small/little) which could both equally well be used for the same item, while for other languages there is no simple one-to-one mapping: they may have multiple specific words which together cover one meaning on the list (Navajo, for instance, has no single word for water, but instead separate words for drinking water, rain water and stagnant water (Campbell, 2004), or they may have one single word which covers more than one item on the list (e.g. bark and skin). Assuming such problem can be satisfactorily overcome, a cognate coding matrix is then created from the completed list, coding all attested cognates (i.e. words which can be shown to derive from a common ancestor) for each meaning with the same state. It is clear, therefore, that phylogenetic models rely not only on the existence of a validated Swadesh-style list, but also on the reliable prior application of the comparative method to accurately identify the cognates and to successfully exclude as many borrowings as possible.

The simplest lexicostatistical models quantify the level of relatedness between languages simply by counting the number of cognate items across the list: the higher the percentage of cognate vocabulary items, the more closely related the languages are assumed to be. More sophisticated models focus not just on a simple distance measure between languages (see Chapter 6 by Ginsburg and Weber for a detailed account of how linguistic distances can be calculated), but on producing an evolutionarily plausible route by which related languages have derived from a common ancestor language, finding the best tree for the largest number of cognate items. The most straightforward of these methods uses an assumption of parsimony similar to that assumed in the comparative method: the best tree is simply the one which minimises the number of evolutionary changes which are required to arrive at the observed data. Maximum parsimony models have been successfully used to analyse the internal history of the Bantu language family, by for instance (Holden, 2002). Maximum compatibility trees are similar to maximum parsimony trees, but require in addition that languages with the same state for a particular meaning are represented as a single group within the tree, therefore ruling out the independent (convergent, in biological terms) evolution of cognates in different lineages of languages; such a model has been used by Nakhleh et al. (2005) to analyse Indo-European. In both cases, the analysis frequently results in several possible best-scoring trees, and so consensus trees which amalgamate these together are often used in order to visualise the results: strict consensus trees include only those splits which are in every one of the best-scoring trees, while majority consensus trees contain those which occur in more than half of 
them.

Other models make explicit assumptions about a particular hypothesis of linguistic change, and then estimate the evolutionary history of the languages of language families based on that hypothesis. A maximum likelihood analysis tries to find a single tree and model parameters which maximise the probability of producing the observed data, while Bayesian methods (Pagel and Meade, 2004) produce a probability distinction over the set of trees, allowing the explicit representation of phylogenetic uncertainty. Gray and Atkinson (2003), for instance, used a Bayesian model to establish the relationship between the frequency of usage and the rate of lexical change in four separate Indo-European languages. Unfortunately, the space of possible trees is enormous and highly skewed towards trees with low likelihood values, and there is no existing algorithm which can guarantee that the best tree will be found in reasonable computing time (Schmidt and von Haeseler, 2009); the best way round this is to use Markov Chain Monte Carlo sampling to move through the space until a stationary distribution is reached, and then build a consensus tree from the trees within the stationary distribution.

One key issue with all such phylogenetic models, however, is their accuracy, which of course depends upon the encoding and analysis of the data. Problematically, because we know only incomplete information about the true history of most languages, it can be difficult to evaluate the different models, although this is done to some extent by calibrating them on well-established language families for which extremely strong written evidence or historical records exist. Another, more subtle, problem with family trees as a model of language history, as mentioned in subsection 2.3.2, is that they force an idealised view of language change which deliberately ignores all kinds of borrowing or influence from unrelated languages, and is completely unable, for instance, to represent the formation of creole languages which have multiple parents. For languages with extensive borrowing, network models are needed in order to be able to represent these conflicting relationships by reticulated joins between branches. Holden and Gray (2006), for instance, used a network model to try to resolve some of the outstanding problems in Bantu history which had proved intractable to tree-based analysis, and found that while West Bantu scattered very quickly into a number of different branches, East Bantu was characterised by extensive borrowing early in its development. The complexity of network models, however, and in particular their sensitivity to changes in internal parameter settings, can make them extremely different to interpret (McMahon and McMahon, 2005).

Much effort in the past few decades has been expended on connecting evidence about language histories with evidence from other disciplines, in order 
to shed further light on aspects of human history, seeking to correlate linguistic family trees or models more generally with archaeological or genetic evidence. The earliest and most famous of these was Cavalli-Sforza et al.'s (1988) attempted reconstruction of human phylogeny by finding correlations between linguistic trees and trees of genetic diversity, which was based on the innovative and intuitively appealing idea that when populations split and merge, both their genes and their languages could have been affected by common processes. There are clear and seductive parallels not only between direct genetic and historical linguistic inheritance, but also between processes of diffusion such as gene exchange through marriage and language convergence through borrowing. Despite this, the work has met with a considerable degree of criticism from many different quarters, not only due to its reliance on many of the extremely contentious linguistic groupings described in subsection 2.3.2 above, but also due to methodological shortcomings in the production of the genetic trees and apparent analytical sleights of hand. The genetic trees were in fact phenograms reflecting overall genetic similarity between populations, which were simply assumed to be equivalent to the phylogeny of the populations without any further evidence (Bateman et al., 1990). The individual population groupings used were also problematic, with a minority of them being explicitly defined on the basis of the language spoken in their community, calling into question the independence of the genetic and linguistic trees which is required for any correlations to be valuable (McMahon and McMahon, 2005). Most seriously of all, the 'remarkable correspondence' between the genetic and linguistic trees claimed by Cavalli-Sforza et al. (1988, p.6002) appears under closer examination to be illusory and largely due to the way in which the trees were visually presented: almost half of the linguistic families are matched with just a single population, and thus have no effect on the congruence of the trees at all (McMahon and McMahon, 1995), most of the other linguistic families are in fact split across different genetic populations, and neither of the putative linguistic superphyla in the linguistic trees (Nostratic and Eurasiatic) corresponds to any population aggregate on the genetic tree (Bateman et al., 1990).

Less controversially, linguistic evidence from phylogenetic analysis has been used to evaluate competing archaelogical hypotheses about human history. Gray and Jordan (2000), for instance, used a maximum parsimony model to derive a tree of 77 Austronesian languages which they showed to be significantly congruent with another tree representing the 'express train' model of the human colonisation of the Pacific, supporting the theory of colonisation by an original population in Taiwan which spread through a series of migrations to Polynesia. A similar parsimony analysis was also used by Holden (2002) to 
reconstruct the family history of the Bantu languages, who showed that the resultant tree closely mirrored existing archaeological evidence about the spread of farming in sub-Saharan Africa in the Neolithic and Early Iron Age.

Phylogenetic models have also been used for the purposes of glottochronology, a technique originally developed through analogy with carbon dating to estimate the dates of events in language family trees, particularly language splits. As in radioactive decay, the method assumed a 'statable regularity' (Lees, 1953, p. 113) in the rate at which basic vocabulary items would be replaced by new words. By averaging results derived from control data based on pairs of languages which could be independently dated (e.g. Latin and Spanish; Old Norse and Modern Swedish) and for which cognacy judgements were carried out using the standard comparative method, Lees (1953) derived a value of 0.8048 ( \pm 0.0176) per millennium for this glottochronological constant. Dating language splits is inherently troublesome because they represent gradual processes rather than precise historical events, but more problematically, by analysing further pairs of languages, Bergslund and Vogt (1962) were able to show that the glottochronological constant was actually an illusion, with widely varying rates of language change depending on a range of different factors such as the relative isolation of the language community and their specific cultural practices; 10 additional work has since shown that languages tend to change more quickly in smaller communities (Nettle, 1999), and that the emergence of a distinct language itself is associated with rapid, punctuated bursts of change followed by much longer periods of slower changes as the new language diverges from its ancestor (Atkinson et al., 2008). More recent phylogenetic models have begun to take account of varying rates of change, again borrowing methods from biology (Drummond and Suchard, 2010) to incorporate both probabilistic variation across the whole tree (relaxed clock models) and a series of different rates for different regions of the tree (random local clock models). In a famous example of this, for instance, Gray and Atkinson (2003) used a maximum likelihood model with a relaxed clock and smoothed variation across the tree, which they used to estimate an emergence date for Indo-European at around 8000-9500 years ago, strongly consistent with an Anatolian origin for the language and its subsequent expansion in association with the spread of agriculture.

\footnotetext{
${ }^{10}$ They describe a word taboo in East Greenlandic, for instance, where the name of a dead person cannot be mentioned during a mourning period; as people's names are often words in the language, new words need to be deliberately (and frequently) created to replace the taboo items.
} 


\subsubsection{Models of language evolution}

Early models of language evolution were dominated by simple computer simulations exploring the biological evolution of the critical period for language learning (Hurford, 1991) and of symbols themselves (Hurford, 1989). Proponents of cultural explanations of the evolution of language, on the other hand, have shown that language acquisition is underpinned by general learning strategies rather than a language organ, showing for instance that learners can extract sufficient information from the transitional probabilities between words to be able to make successful grammaticality judgements in complex sentences (Reali and Christiansen, 2005) and that distributional information of this sort can be integrated with probabilistic phonological cues to create accurate representations of lexical categories (Reali et al., 2003). Such simulations are typically agent-based models, involving a simulated population of individuals (agents) initially endowed with some specified cognitive capacities and then left to interact with each other and update their linguistic knowledge over thousands of interactions and perhaps over multiple generations of agents dying and being replaced. This kind of modelling has been used to explore a wide range of issues from the emergence of phonological structure and the duality of patterning described in Section 2.2 (de Boer, 2001: Oudever. 2006; Zuidema and de Boer. 2009) to the evolution of vocabulary (Smith, 2004) and syntactic structure (Kirby, 2000). More recently, a whole research programme (Steels, 2011) has been developed on the implementation of agent-based language game models, which model the emergence of aspects of language through the interactive negotiation of co-ordinated behaviour between agents, not only general concepts like the development of shared lexicons (Steels, 1999; Smith, 2005: Steels and Belpaeme, 2005) and the design feature of compositionality (Vogt, 2005), but also more focused grammatical and morphological features such as the emergence of case systems (van Trijp, 2012) and agreement (Beuls and Steels, 2013) through processes of grammaticalisation.

Probably the primary agent-based model, which has now outgrown its computational origins to be used frequently in both mathematical and experimental models as well, is the iterated learning model (Kirby and Hurford, 2002; Smith et al., 2003b), which allows explorations of how the structure of language evolves through its transmission over a diffusion chain, with agents learning language through observing the linguistic usage of other agents who learnt their language in the same way. Simple iterated learning models have been instrumental in demonstrating the importance of cultural evolution in the evolution of language, showing how random languages can be transformed into stable, syntactically complex languages simply by being learnt over generations through a so-called transmission bottleneck. This term refers to the fact 
that learners have to learn from only partial experience of the language, and so have not explicitly learnt how to express certain meanings. The transmission bottleneck forces learners to generalise from the data they have encountered to represent such unobserved meanings, and this pressure biases the language towards compositionality and systematicity, rather than the idiosyncrasy which can persist without the bottleneck (Kirby, 2001; Smith et al., 2003a).

In the last decade, a set of experimental techniques has become popular in work on the dynamics of language evolution. The iterated learning model itself was transferred to this paradigm in a celebrated language experiment in which an unstructured 'alien' language of random words, with no connection between meanings and forms, was taught to participants; the words produced for the meanings by this generation were then taught to the next generation of participants (Kirby et al., 2008). Over cumulative generations, the languages adapted so that they were easier to learn, essentially by tolerating massive ambiguity and using the same word for multiple meanings; as a result of this the language's expressive power was lost. A second experiment reintroduced expressivity into the language by the explicit exclusion of ambiguity, and this resulted in the languages adapting differently, still becoming increasingly learnable, but this time by developing compositionality so that aspects of meanings were systematically reflected in the words produced, so that expressivity too was maximised.

In another, graphically-based experiment, the competing pressures of learnability and expressibility were explored differently: Garrod et al. (2007) asked participants to play a Pictionary-style game in which one person draws an ostensive representation of some meaning, and the other infers what the meaning is. When participants play this game repeatedly in pairs, they develop a communicative system which is extremely expressive but in which the signals become increasingly simple after repeated use; the participants no longer need to draw all the detail, but can simply provide shorthand simplified cues to the meanings which effectively reside in their shared common history of use (Caldwell and Smith, 2012). The cues themselves are idiosyncratic and arbitrary, showing clearly how common ground and shared experience can drive the 'drift to the arbitrary' (Tomasello, 2008); this makes languages more internally efficient, but at the expense of learnability. In a further experiment, Theisen et al. (2010) introduced a pressure for learnability by embedding the game in an iterated learning chain, with new generations learning from the drawings produced by the previous generation; in this case the drawings still became increasingly conventionalised and arbitrary, but also developed compositionality, making them more learnable to future generations. More recently, Kirby et al. (2015) use both computational simulations and laboratory 
experiments to show convincingly that linguistic structure emerges culturally, as a direct result of the interactions between the twin pressures of expressivity and learnability.

Experimental techniques have also been used to explore the emergence of signals themselves: in a pioneering use of this technique, Galantucci (2005) investigated the co-ordination and conventionalisation of signalling systems in an artificial context where existing communication systems were rendered useless but with other novel communicative opportunities; participants learnt in many cases to exploit the opportunties and developed shared expressive communicative systems. This paradigm was pared back further by Scott-Phillips et al. (2009) to a situation where participants could only move in a strictly controlled fashion around a small grid, yet needed to communicate successfully in order to co-ordinate their behaviour. Despite this extremely challenging situation, participants were able to develop successful communication systems, if they were able to signal their communicative intent by moving ostensively in a distinctive manner contrary to their expectations.

The controversy over Cavalli-Sforza et al.'s (1988) work, described in subsection 2.4.2, cast a long shadow over work comparing genetics and linguistics for a considerable period of time, but over the last few years it has become clear that genes can have potentially surprising effects on linguistic structures. Dediu and Ladd (2007) first demonstrated the existence of a fascinating relationship at the population level between the allele frequencies in the population of two genes involved in brain development and the likelihood of the languages being spoken in the population having the tonal contrasts described in subsection 2.2.1. Intriguingly, the two genes in question, ASPM and Microcephalin, have both emerged relatively recently in human evolution and are spreading quickly across the world, suggesting that they are favoured by natural selection and therefore that the correlation reflects some kind of small cognitive bias whose effects on language structure only become detectable after many generations of cultural evolution, although Dediu and Ladd are careful not to speculate on the precise details of this bias. The significance of the relationship was demonstrated by taking advantage of new large genetic and linguistic databases (Haspelmath et al., 2005) to test many thousands of other possible relationships, showing that although there is generally no relationship between genetic markers and linguistic features, the relationship between these two genes and tonal languages remained very strong. Similar correlations have been noted before, notably between linguistic diversity and biodiversity (Nettle, 1999; Maffi, 2001), but increases in the availability and ease of use of such databases has led over recent years to considerable growth in correlational studies searching for relationships between combina- 
tions of linguistic variables and other cultural traits, although researchers must be careful to avoid simplistic uncontrolled data dredging over many different variables, which will inevitably uncover spurious relationships (Roberts and Winters, 2013). Interestingly, many correlational studies have found evidence, however, for the evolutionary adaptation of aspects of languages to particular ecological and social niches in their dynamic environment. Lupyan and Dale (2010), for instance, showed an inverse correlation between population size and morphological complexity, finding evidence in support of Wray and Grace's (2007) theory that exoteric (outward-facing) languages used in large, disparate communities (such as English and Swahili) face pressure to be more easily learnable by non-native speakers and to be easily used by people from different backgrounds with little non-linguistic common ground, while esoteric (inward-facing) languages in small communities (such as Tatar and Elfdalian) face contrasting pressures to become reliable social markers of community membership, and thus showed increases in morphological complexity and opacity to ensure that only people able to spend a great deal of effort would be able to use them. Sometimes, the niche is physiological, such as Everett's (2013) findings that the languages spoken in populations living at high altitudes have more ejective consonants, from which he hypothesises that this may be due to lower air pressure making ejectives easier to articulate or that ejectives mitigate the dehydrating effects of exhalation in drier climates. This line of inquiry has been extended more recently, with Everett et al. (in press) showing that extremely cold and dry regions constrain the emergence and spread of tonal languages, because the reduced air quality appears to compromise the fine control needed to maintain the tonal distinctions.

\subsection{Conclusion}

The question of what makes human language special has been long debated and analysed, with its expressive power in particular often regarded with a reverential sense of awe and wonder. This paper has focused on one crucial characteristic of language: its dynamic nature, which marks it as unique and rather strange in comparison to other communication systems. All languages are in a state of constant flux, characterised by dynamic variation and massive diversity at all levels of analysis. In Section 2.2, I gave a detailed overview of some of the striking ways in which this diversity is manifested across different languages, looking at the sounds they use and the way these are organised, the ways in which words are created from their component parts and then assembled into full sentences, and the conceptualisation of simple spatial relationships between objects. 
In Section 2.3, I set out three of the main timescales on which research into language change and evolution is carried out. The fundamental basis of linguistic change is its pervasive cumulative variation, which is primarily caused by the complex social functions for which language is used, and the nature of language in use, in particular its constant oscillation between internal linguistic representations and external linguistic behaviour, mediated by the cooperative communicative processes of ostension and inference. This pervasive variation leads to the constant creation of new linguistic varieties, which over time and space, develop into separate languages stemming from a common source; much early work in linguistics as a scientific discipline, in fact, was in the identification of relationships between modern languages and in inferring and describing their shared and separate histories in terms of family trees and networks. On a yet longer timescale, evolutionary linguistics is interested in the initial emergence of language from a pre-linguistic communication system, particularly in how interactions between biological and cultural evolution can provide explanations of this emergence by investigating language as a complex adaptive system with properties emerging from language use in a social context.

Formal models have proved over the last few decades to be extremely important in the exploration and systematical testing of many aspects of the dynamic nature of language. In Section 2.4, I presented a number of recent models in this vein, including evolutionary models of the propagation of linguistic variants, phylogenetic models of language family histories and their use in wider debates about human history, and formal and experimental models of cumulative cultural evolution showing the adaptive nature of language itself under pressures of learnability and expressivity. It is clear that both the scope and variety of models have increased enormously over recent years, with many different techniques being developed to explore an increasing range of linguistic characteristics; the increased availability of large datasets has led, for instance, to many comparative studies exploring correlations between specific linguistic characteristics and genetic or geographic information. 


\subsection{References}

J. Aitchison (1996) The Seeds of Speech: Language Origin and Evolution (Cambridge: Cambridge University Press).

Q. Atkinson, A. Meade, C. Venditti, S. Greenhill, and M. Pagel (2008) 'Languages evolve in punctuational bursts', Science, 319, 588.

R. Bateman, I. Goddard, R. O'Grady, V. Funk, R. Mooi, J. Krees, and P. Cannell (1990) 'Speaking of forked tongues: the feasibility of reconciling human phylogeny and the history of language', Current Anthropology, 31, 1-24.

G. Baxter, R. Blythe, W. Croft, and A. McKane (2009) 'Modeling language change: an evaluation of Trudgill's theory of the emergence of New Zealand English', Language Variation and Change, 21, 257-296.

C. Beckner, R. Blythe, J. Bybee, M. Christiansen, W. Croft, N. Ellis, J. Holland, J. Ke, D. Larsen-Freeman, and T. Schoenemann (2009) 'Language is a complex adaptive system: Position paper', Language Learning, 59, 1-26.

K. Bergslund and H. Vogt (1962) 'On the validity of glottochronology', Current Anthropology, 3, 115-153.

K. Beuls and L. Steels (2013) 'Agent-based models of strategies for the emergence and evolution of grammatical agreement', PLoS one, 8, 358960.

R. Blythe and W. Croft (2012) 'S-curves and the mechanisms of propagation in language change', Language, 88, 269-304.

D. Bolinger (1975) Aspects of Language (New York: Harcourt Brace Jovanovich).

H. Bowe and S. Morey (1999) The Yorta Yorta (Bangerang) Language of the Murray Goulburn, Including Yabula Yabula (Canberra: Pacific Linguistics).

H. Brighton, K. Smith, and S. Kirby (2005) 'Language as an evolutionary system', Physics of Life Reviews, 2, 177-226. 
P. Brown (2001) 'Learning to talk about motion up and down in Tzeltal: is there a language-specific bias for verb learning?' In M. Bowerman and S. Levinson (eds.) Language Acquisition and Conceptual Development (Cambridge: Cambridge University Press).

P. Brown (2006) 'A sketch of the grammar of space in Tzeltal' In S. Levinson and D. Wilkins (eds.) Grammars of Space: Explorations in Cognitive Diversity (Cambridge: Cambridge University Press).

M. Butskhrikidze (2002) The Consonant Phonotactics of Georgian (Utrecht: Landelijke Onderzoekschool Taalwetenschap).

J. Bybee (2006) 'From usage to grammar: the mind's response to repetition', Language, 82, 711-733.

C. Caldwell and K. Smith (2012) 'Cultural evolution and perpetuation of arbitrary communicative conventions in experimental microsocieties', PLoS one, 7, e43807.

L. Campbell (1988) 'Review of: Language in the Americas, J. H. Greenberg', Language, 64, 591-615.

L. Campbell (2004) Historical Linguistics (Edinburgh: Edinburgh University Press).

L. Campbell and W. Poser (2008) Language Classification: History and Method (Cambridge: Cambridge University Press).

L. Cavalli-Sforza, P. Menozzi, A. Piazza, and J. Mountain (1988) 'Reconstruction of human evolution: bringing together genetic, archaeological and linguistic data', Proceedings of the National Academy of Sciences of the United States of America, 85, 6002-6006.

N. Chater and M. Christiansen (2009) 'Language acquisition meets language evolution', Cognitive Science, 34, 1-27.

N. Chater, F. Reali, and M. Christiansen (2009) 'Restrictions on biological adaptation in language evolution', Proceedings of the National Academy of Sciences of the United States of America, 106, 1015-1020.

M. Chen and W. Wang (1975) 'Sound change: actuation and implementation', Language, 51, 255-281.

N. Chomsky (1965) Aspects of the Theory of Syntax (Cambridge, MA: MIT Press). 
N. Chomsky (1980) Rules and Representations (London: Basil Blackwell).

M. Christiansen and N. Chater (2008) 'Language as shaped by the brain', Behavioral and Brain Sciences, 31, 489-508.

H. Clark (1996) Using Language (Cambridge: Cambridge University Press).

G. Clements (2000) 'Phonology' In B. Heine and D. Nurse (eds.) African Languages: an Introduction (Cambridge: Cambridge University Press).

F. Coulmas (2013) Sociolinguistics: The Study of Speakers' Choices (Cambridge: Cambridge University Press).

W. Croft (2000) Explaining Language Change: An Evolutionary Approach (Singapore: Longman).

B. de Boer (2001) The Origins of Vowel Systems (Oxford: Oxford University Press).

F. de Saussure (1916) Cours de Linguistique Générale (Paris: Payot).

T. Deacon (1997) The Symbolic Species (London: Penguin).

D. Dediu and R. Ladd (2007) 'Linguistic tone is related to the population frequency of the adaptive haplogroups of two brain size genes, ASPM and microcephalin', Proceedings of the National Academy of Sciences of the United States of America, 104, 10944-10949.

G. Deutscher (2010) Through the Language Glass: How Words Colour Your World (London: William Heinemann).

R. Dixon (1972) The Dyirbal Language of North Queensland (Cambridge: Cambridge University Press).

R. Dixon (1997) The Rise and Fall of Languages (Cambridge: Cambridge University Press).

A. Drummond and M. Suchard (2010) 'Bayesian random local clocks, or one rate to rule them all', BioMed Central Biology, 8, 114.

M. Dryer (2013a) 'Order of subject, object and verb' In M. Dryer and M. Haspelmath (eds.) The World Atlas of Linguistic Structures Online (Leipzig: Max Planck Institute for Evolutionary Anthropology). 
M. Dryer (2013b) 'Prefixing vs. suffixing in inflectional morphology' In M. Dryer and M. Haspelmath (eds.) The World Atlas of Linguistic Structures Online (Leipzig: Max Planck Institute for Evolutionary Anthropology).

N. Evans (2010) Dying Words: Endangered Languages and What They Have to Tell Us (Singapore: Wiley-Blackwell).

N. Evans and S. Levinson (2009) 'The myth of language universals: Language diversity and its importance for cognitive science', Behavioral and Brain Sciences, 32, 429-492.

C. Everett (2013) 'Evidence for direct geogaphic influences on linguistic sounds: the case of ejectives', PLoS one, 8, e65275.

C. Everett, D. Blasi, and S. Roberts (in press) 'Climate, vocal folds, and tonal languages: connecting the physiological and geographic dots', Proceedings of the National Academy of Sciences.

G. Fauconnier and M. Turner (2002) The Way We Think: Conceptual Blending and the Mind's Hidden Complexities (New York: Basic Books).

W. Foley (1997) Anthropological Linguistics: An Introduction (London: Blackwell).

B. Galantucci (2005) 'An experimental study of the emergence of human communication systems', Cognitive Science, 29, 737-767.

S. Garrod, N. Fay, J. Lee, J. Oberlander, and T. MacLeod (2007) 'Foundations of representations: where might graphical symbol systems come from?', Cognitive Science, 31, 961-987.

M. Gell-Mann (1994) The Quark and the Jaguar (New York: Freeman).

C. Goddard (2005) The Languages of East and Southeast Asia (Oxford: Oxford University Press).

T. Gong, L. Shuai, M. Tamariz, and G. Jäger (2012) 'Studying language change using Price equation and Pólya-urn dynamics', PLoS one, 7, e33171.

R. Gray and Q. Atkinson (2003) 'Language-tree divergence times support the Anatolian theory of Indo-European origins', Nature, 426, 435-439.

R. Gray and F. Jordan (2000) 'Language trees support the express-train sequence of Austronesian expansion', Nature, 405, 1052-1055. 
J. Greenberg (1963) 'Some universals of grammar with particular reference to the order of meaningful elements' In J. Greenberg (ed.) Universals of Language (Cambridge, MA: MIT Press), 2nd edition.

J. Greenberg (1987) Language in the Americas (Stanford, CA: Stanford University Press).

R. Greenberg (2004) Language and Identity in the Balkans: Serbo-Croatian and its Disintegration (Oxford: Oxford University Press).

P. Grice (1975) 'Logic and conversation' In P. Cole and J. Morgan (eds.) Syntax and Semantics, volume 3 (New York: Academic Press).

C. Hall (1988) 'Integrating diachronic and processing principles in explaining the suffix preference' In J. Hawkins (ed.) Explaining Language Universals (Oxford: Blackwell).

R. Harlow (2007) Māori: A Linguistic Introduction (Cambridge: Cambridge University Press).

S. Harrison (2005) 'On the limits of the comparative method' In B. Joseph and R. Janda (eds.) The Handbook of Historical Linguistics (Oxford: Blackwell).

M. Haspelmath, M. Dryer, D. Gil, and B. Comrie (eds.) (2005) The World Atlas of Linguistic Structures (Oxford: Oxford University Press).

M. Hauser, N. Chomsky, and T. Fitch (2002) 'The faculty of language: what is it, who has it and how did it evolve?', Science, 298, 1569-1579.

B. Heine and T. Kuteva (2005) Language Contact and Grammatical Change (Cambridge: Cambridge University Press).

B. Heine and T. Kuteva (2006) The Changing Language of Europe (Oxford: Oxford University Press).

C. Hockett (1960) 'The origin of speech', Scientific American, 203, 88-96.

S. Höfler and A. Smith (2009) 'The pre-linguistic basis of grammaticalisation: a unified approach to metaphor and reanalysis', Studies in Language, 33, 886-909.

C. Holden (2002) 'Bantu language trees reflect the spread of farming across sub-Saharan Africa: a maximum-parsimony analysis', Proceedings of the Royal Society B, 269, 793-799. 
C. Holden and R. Gray (2006) 'Rapid radiation, borrowing, and dialect continua in the Bantu languages' In P. Forster and C. Renfrew (eds.) Phylogenetic Methods and the Prehistory of Languages (Cambridge: MacDonald Institute Press).

J. Holmes (2013) An Introduction to Sociolinguistics (Abingdon: Routledge), 4th edition.

P. Hopper (1987) 'Emergent grammar', Berkeley Linguistics Conference (BLS), $13,139-157$.

D. Hull (1988) Science as a Process: An Evolutionary Account of the Social and Conceptual Development of Science (Chicago: University of Chicago Press).

J. Hurford (1989) 'Biological evolution of the Saussurean sign as a component of the language acquisition device', Lingua, 77, 187-222.

J. Hurford (1991) 'The evolution of critical period for language acquisition', Cognition, 40, 159-201.

M. Israel (2014) 'Semantics: how language makes sense' In C. Genetti (ed.) How Languages Work: An Introduction to Language and Linguistics (Cambridge: Cambridge University Press).

A. Kandler, R. Unger, and J. Steele (2010) 'Language shift, bilingualism and the future of Britain's Celtic languages', Philosophical Transactions of the Royal Society of London, series B - Biological Sciences, 365, 3855-3864.

A. Kassian, G. Starostin, A. Dybo, and V. Chernov (2010) 'The Swadesh wordlist: an attempt at semantic specification', Journal of Language Relationship, 4, 46-89.

A. Kinsella (2009) Language Evolution and Syntactic Theory (Cambridge: Cambridge University Press).

S. Kirby (2000) 'Syntax without natural selection: how compositionality emerges from vocabulary in a population of learners' In C. Knight, M. Studdert-Kennedy, and J. Hurford (eds.) The Evolutionary Emergence of Language: Social Function and the Origins of Linguistic Form (Cambridge: Cambridge University Press).

S. Kirby (2001) 'Spontaneous evolution of linguistic structure: an iterated learning model of the emergence of regularity and irregularity', IEEE Journal of Evolutionary Computation, 5, 102-110. 
S. Kirby and J. Hurford (2002) 'The emergence of linguistic structure: an overview of the iterated learning model' In A. Cangelosi and D. Parisi (eds.) Simulating the Evolution of Language (London: Springer Verlag).

S. Kirby, H. Cornish, and K. Smith (2008) 'Cumulative cultural evolution in the lab: an experimental approach to the origins of structure in human language', Proceedings of the National Academy of Sciences, 105, 10681-10686.

S. Kirby, M. Tamariz, H. Cornish, and K. Smith (2015) 'Compression and communication in the cultural evolution of linguistic structure', Cognition, 141, 87-102.

M. Krauss (1992) 'The world's languages in crisis', Language, 68, 4-10.

M. Krifka (2001) 'Compositionality' In R. Wilson and F. Keil (eds.) The MIT Encyclopedia of the Cognitive Sciences (Cambridge, MA: MIT Press).

W. Labov (1972) Sociolinguistic Patterns (Philadelphia: University of Pennsylvania Press).

P. Ladefoged and K. Johnson (2011) A Course in Phonetics (London: Wadsworth), 6th edition.

R. Lees (1953) 'The basis of glottochronology', Language, 29, 113-127.

S. Levinson (1997) 'Language and cognition: the cognitive consequences of spatial description in Guugu Yimithirr', Journal of Linguistic Anthropology, 7, 98-131.

S. Levinson (2006) 'The language of space in Yélî Dnye' In S. Levinson and D. Wilkins (eds.) Grammars of Space: Explorations in Cognitive Diversity (Cambridge: Cambridge University Press).

S. Levinson and D. Wilkins (eds.) (2006) Grammars of Space: Explorations in Cognitive Diversity (Cambridge: Cambridge University Press).

P. Lewis (ed.) (2005) Ethnologue: Languages of the World (Dallas: SIL International).

G. Lupyan and R. Dale (2010) 'Language structure is partly determined by social structure', PLoS one, 5, e8559.

L. Maffi (ed.) (2001) On Biocultural Diversity: Linking Language, Knowledge and the Environment (Washington: Smithsonian Institute Press). 
A. Martinet (1949) 'La double articulation linguistique', Travaux du Cercle Linguistic de Copenhague, 5, 30-37.

W. McGregor (2006) 'Prolegomenon to a Warrwa grammar of space' In S. Levinson and D. Wilkins (eds.) Grammars of Space: Explorations in Cognitive Diversity (Cambridge: Cambridge University Press).

A. McMahon (1994) Understanding Language Change (Cambridge: Cambridge University Press).

A. McMahon and R. McMahon (1995) 'Linguistics, genetics and archaeology: internal and external evidence in the Amerind controversy', Transactions of the Philological Society, 93, 125-225.

A. McMahon and R. McMahon (2000) 'Problems of dating and time depth in linguistics and biology' In C. Renfrew, A. McMahon, and L. Trask (eds.) Time Depth in Historical Linguistics (2 vols.) (Cambridge: McDonald Institute for Archaeological Research).

A. McMahon and R. McMahon (2003) 'Finding families: quantitative methods in language classification', Transactions of the Philological Society, 101, 7-55.

A. McMahon and R. McMahon (2005) Language Classification by Numbers (Oxford: Oxford University Press).

J. Milroy (1980) Language and Social Networks (Oxford: Blackwell).

M. Mithun (1991) 'Active/agentive case marking and its motivations', Language, 67, 510-546.

E. Moore (2004) 'Sociolinguistic style: a multidimensional resource for shared identity creation', Canadian Journal of Linguistics, 49, 375-396.

S. Mufwene (2002) 'Competition and selection in language evolution', Selection, 3, 45-56.

S. Munroe and A. Cangelosi (2002) 'Learning and the evolution of language: the role of cultural variation and learning costs in the Baldwin Effect', Artificial Life, 8, 331-339.

L. Nakhleh, D. Ringe, and T. Warnow (2005) 'Perfect phylogenetic networks: A new methodology for reconstructing the evolutionary history of natural languages', Language, 81, 382-420. 
D. Nettle (1999) 'Is the rate of linguistic change constant?', Lingua, 108, 119136.

D. Nettle and S. Romaine (2000) Vanishing Voices: The Extinction of the World's Languages (Oxford: Oxford University Press).

P.-Y. Oudeyer (2006) The Self-Organization of Speech (Oxford: Oxford University Press).

M. Pagel and A. Meade (2004) 'A phylogenetic mixture model for detecting pattern-heterogeneity in gene sequence of character-state data', Systematic Biology, 53, 571-581.

J. Pierrehumbert, M. Beckman, and R. Ladd (2000) 'Conceptual foundations of phonology as a laboratory science' In N. Burton-Roberts, P. Carr, and G. Docherty (eds.) Conceptual and Empirical Foundations of Phonology (Cambridge: Cambridge University Press).

S. Pinker and P. Bloom (1990) 'Natural language and natural selection', Behavioral and Brain Sciences, 13, 707-784.

G. Price (1970) 'Selection and covariance', Nature, 227, 520-521.

G. Pullum and B. Scholz (2002) 'Empirical assessment of stimulus poverty arguments', The Linguistic Review, 19, 9-50.

F. Reali and M. Christiansen (2005) 'Uncovering the richness of the stimulus: structure dependence and indirect statistical evidence', Cognitive Science, $29,1007-1028$.

F. Reali, M. Christiansen, and P. Monaghan (2003) 'Phonological and distributional cues in syntax acquisition: scaling up the connectionist approach to multiple-cue integration' In R. Alterman and D. Kirsh (eds.) Proceedings of the 25th Annual Conference of the Cognitive Science Society (Boston: Lawrence Erlbaum Associates).

S. Roberts and J. Winters (2013) 'Linguistic diversity and traffic accidents: lessons from statistical studies of cultural traits', PLoS one, 8, e70902.

E. Round (2009) 'Kayardild morphology, phonology and morphosyntax', Ph.D. thesis, Yale University.

M. Ruhlen (1991) A Guide to the World's Languages (London: Arnold). 
M. Ruhlen (1994) On the Origin of Languages: Studies in Linguistic Taxonomy (Stanford, CA: Stanford University Press).

G. Sankoff (2004) 'Linguistic outcomes of language contact' In J. Chambers, P. Trudgill, and N. Schilling-Estes (eds.) The Handbook of Language Variation and Change (Oxford: Wiley).

H. Schmidt and A. von Haeseler (2009) 'Phylogenetic inference using maximum likelihood methods' In P. Lemey, M. Salemi, and A. Vandamme (eds.) The Phylogenetic Handbook: a Practical Approach to Phylogenetic Analysis and Hypothesis Testing. (Cambridge: Cambridge University Press).

E. Schultze-Berndt (2006) 'Sketch of a Jaminjung grammar of space' In S. Levinson and D. Wilkins (eds.) Grammars of Space: Explorations in Cognitive Diversity (Cambridge: Cambridge University Press).

T. Scott-Phillips (2014) Speaking Our Minds: Why Human Communication is Different, and How Language Evolved to Make it Special (London: Palgrave MacMillan).

T. Scott-Phillips, S. Kirby, and G. Ritchie (2009) 'Signalling signalhood and the emergence of communication', Cognition, 113, 226-233.

C. Shannon (1948) 'A mathematical theory of communication', Bell System Technical Journal, 27, 379-423 and 623-656.

P. Siptár and M. Törkenczy (2000) The Phonology of Hungarian (Oxford: Oxford University Press).

A. Smith (2005) 'The inferential transmission of language', Adaptive Behavior, $13,311-324$.

A. Smith (2008) 'Protolanguage reconstructed', Interaction Studies, 9, 100-116.

A. Smith and S. Höfler (2015) 'The pivotal role of metaphor in the evolution of human language' In J. Díaz Vera (ed.) Metaphor and Metonymy across Time and Cultures (Berlin: Mouton de Gruyter).

K. Smith (2004) 'The evolution of vocabulary', Journal of Theoretical Biology, 228, 127-142.

K. Smith (2011) 'Why formal models are useful for evolutionary linguists' In K. Gibson and M. Tallerman (eds.) Oxford Handbook of Language Evolution (Oxford: Oxford University Press). 
K. Smith and S. Kirby (2008) 'Cultural evolution: implications for understanding the human language faculty and its evolution', Philosophical Transactions of the Royal Society of London, series B - Biological Sciences, 363, 35913603.

K. Smith, H. Brighton, and S. Kirby (2003a) 'Complex systems in language evolution: the cultural emergence of compositional structure', Advances in Complex Systems, 6, 537-558.

K. Smith, S. Kirby, and H. Brighton (2003b) 'Iterated learning: a framework for the emergence of language', Artificial Life, 9, 371-386.

J.-J. Song (2001) Linguistic Typology: Morphology and Syntax (Harlow: Longman).

D. Sperber and D. Wilson (1995) Relevance: Communication and Cognition (Oxford: Blackwell).

L. Steels (1999) The Talking Heads Experiment (Antwerpen: Laboratorium), special pre-edition.

L. Steels (ed.) (2011) Design Patterns in Fluid Construction Grammar (Amsterdam: John Benjamins).

L. Steels and T. Belpaeme (2005) 'Coordinating perceptually grounded categories through language: a case study for colour', Behavioral and Brain Sciences, 28, 469-529.

M. Swadesh (1952) 'Lexico-statistic dating of prehistoric ethnic contacts', Proceedings of the American Philosophical Society, 96, 453-463.

L. Talmy (2000) Towards a Cognitive Semantics (Cambridge, MA: MIT Press).

C. Theisen, J. Oberlander, and S. Kirby (2010) 'Systematicity and arbitrariness in novel communication systems', Interaction Studies, 11, 14-32.

M. Tomasello (2008) Origins of Human Communication (Harvard: MIT Press).

M. Tomasello, M. Carpenter, J. Call, T. Behne, and H. Moll (2005) 'Understanding and sharing intentions: The origins of cultural cognition', Behavioral and Brain Sciences, 28, 675-735.

L. Trask (1996) Historical Linguistics (London: Arnold). 
G. Trousdale (2010) An Introduction to English Sociolinguistics (Edinburgh: Edinburgh University Press).

P. Trudgill (1972) 'Sex, covert prestige, and linguistic change in the urban British English of Norwich', Language in Society, 1, 179-196.

P. Trudgill (2008) 'Colonial dialect contact in the history of European languages: on the irrelevance of identity to new-dialect formation', Language in Society, 37, 241-280.

W. Turkel (2002) 'The learning guided evolution of natural language' In E. Briscoe (ed.) Linguistic Evolution through Language Acquisition: Formal and Computational Models (Cambridge: Cambridge University Press).

R. van Trijp (2012) 'The evolution of case systems for marking event structure' In L. Steels (ed.) Experiments in Cultural Language Evolution (Oxford: John Benjamins).

P. Vogt (2005) 'The emergence of compositional structures in perceptually grounded language games', Artificial Intelligence, 167, 206-242.

A. Wedel (2006) 'Exemplar models, evolution and language change', The Linguistic Review, 23, 247-274.

A. Wray and G. Grace (2007) 'The consequences of talking to strangers: evolutionary corollaries of socio-cultural influences on linguistic form', Lingua, 117, 543-578.

H. Yamauchi (2001) 'The difficulty of the Baldwinian account of linguistic innateness' In J. Kelemen and P. Sosík (eds.) Advances in Artificial Life: Proceedings of the 6th European Conference on Artificial Life (Heidelberg: Springer-Verlag).

E. Zsiga (2013) The Sounds of Language: An Introduction to Phonetics and Phonology (Oxford: Wiley-Blackwell).

W. Zuidema (2003) 'How the poverty of the stimulus solves the poverty of the stimulus' In S. Becker, S. Thrun, and K. Obermayer (eds.) Advances in Neural Information Processing Systems 15 (Proceedings of NIPS '02) (Cambridge, MA: MIT Press).

W. Zuidema and B. de Boer (2009) 'The evolution of combinatorial phonology', Journal of Phonetics, 37, 125-144. 


\section{Bio}

Andrew Smith is Lecturer in Language Studies at the University of Stirling. He received his $\mathrm{PhD}$ in Language Evolution from the University of Edinburgh. His main research interests are in evolutionary and cognitive linguistics, focusing in particular on grammaticalisation, the inferential socio-cultural and cognitive bases of communication, metaphor, cultural evolution and word learning mechanisms. His most recent book is the edited collection New Directions in Grammaticalization Research (with Graeme Trousdale and Richard Waltereit), published by John Benjamins in 2015.

\section{Index Terms}

\section{General}

comparative method, complex adaptive system, cultural evolution, evolution of language, iterated learning, language change, language diversity, language evolution, lexicostatistics, linguistic variation, model, morphology, phonology, phylogeny, simulation,

\section{Languages and Language Families}

Amerind, Arabic, Austronesian, Bantu, Basque, Bosnian, Cantonese, Catalan, Celtic, Croatian, Dutch, Dyirbal, East Greenlandic, Elfdalian, English, Eurasiatic, French, Gaelic, Georgian, Greek, Guaraní, Guru Yimithirr, Hawai'ian, Hebrew, Hungarian, Indo-European, Indo-Pacific, Italian, Jaminjung, Japanese, Kayardild, Khoisan, Kihunde, Lakhota, Latin, Mandarin, Māori, Montenegrin, Navajo, Nostratic, Old Norse, Polish, Portuguese, Proto-Germanic, Proto-IndoEuropean, Proto-World, Rotokas, Serbian, Serbo-Croat, Shona, Spanish, Swahili, Swedish, Tagalog, Tatar, Thai, Tzeltal, Warrwa, West Germanic, Yélî Dnye, Yorta Yorta, Yup'ik 